\title{
Optimization of the Sheet Metal Base of a Toggle Clamp Using Finite Element Method
}

\author{
P.K. KAUYUKA, Q. QIU, J.D. AyANO, E.K. BleSSinG, H. LiU \\ University of Debrecen, Faculty of Engineering, Department of Mechanical Engineering, pkkauyuka@gmail.com, \\ 371218040@qq.com, ayanojeremiah@gmail.com, blessemma10292@gmail.com,1421363026@qq.com
}

\begin{abstract}
Optimization relates to the ultimate yield strength and the maximum stress incident on the current model under critical working conditions and finds through iterative processing a way to compensate for the strength requirement without going beyond the desired mass limits. In this paper, the horizontal sheet metal base of a horizontal toggle clamp is optimised for mass reduction using the finite element analysis in the computer aided design software. The sheet metal base material is the ANSI32 Steel. In the design software, it is designed with the thickness of $7 \mathrm{~mm}$ and it is intended to support a workload of up to $750 \mathrm{~N}$. The constraints were a fixed point added at all the holes and at the bottom surface of the sheet metal base. A number of iterations were made for the 750N loading force across the base plate to run the simulation. For optimization, the aim was to minimize the mass of the base plate. The design parameters were Von Mises, factor of safety and displacement. The variables were the slots' width and material thickness along the mid-surface of the sheet metal. The mass was reduced by more than thirty per cent overall.
\end{abstract}

Keywords: sheet metal, optimization, mass reduction, finite element analysis

\section{Introduction}

Mass reduction is one of the most targeted results in various engineering design applications. For various reasons, an engineering part with a lighter weight is preferred due to numerous advantages. In an automotive industry, for example, there is a goal to reduce the weight of the cars. A lighter car can have better acceleration, and hence a better performance; it involves less material cost, and it has better fuel efficiency which means that the vehicle exhaust emissions are also reduced [1]. In the pipeline systems, brackets are commonly used for making pipeline supports. Some of these brackets were designed to contain a lot of material but it does not contribute to the general purpose of withstanding pipeline load. Some of this material could be removed to achieve less mass as well as less cost in the brackets production [2].

In railway vehicles, mass is also a very critical parameter as it has an impact on a pressure applied on a rail track by each wheel of the vehicle. If this pressure is too high, it can increase the wear rate of both the rails and the wheels, resulting in more frequent wheels replacements, railway infrastructure repairs, reduced efficiency of the vehicle, high energy demand for accelerating and stopping the vehicle, etc. It is essential to minimize such mass in order to lower the running costs of the vehicle and negative impact on the environment [3]. There are various other industries in which mass reduction in engineering parts is necessary for better performance, cost effectiveness, environmental perseverance, etc. 
Mass reduction of engineering parts can be achieved using several optimization methods including numerical calculations, computer aided design software, generative design, and so on. In engineering design, optimization is an objective to maximize the performance, while minimizing the utilization of materials used in an engineering part, within the subjected constraints [4]. The engineering optimization process aims to find minimum cost to do the function depending on design variable factors, and the final optimized part will need to satisfy the working conditions. The response and performance of the optimized product can be analysed using finite element methods to check if the part is sufficiently optimized or not, and if not, then the optimization can be modified in iterations [5].

In previous studies, Ziech et. al. (2003) made an optimization of computer aided design models along with iterations of finite element analysis of the models to enhance the shape, stiffness and weight, to design lightweight components [6]. Shinde and Kajale (2012) used design optimization in a rotary tillage tool system component by using computer aided engineering analysis in which the rotary tillage blade was modified using computer aided design model and it was physically tested resulting in high weed removal efficiency and excellent soil bed performance [7], a highly desired result.

Mandal et. al. (2014) used the computer aided design method to design and develop suitable blade with an enhanced service life [8]. Vaishnav et. al. (2016) made a design and optimization of top plate which holds the hydraulic cylinder of the press machine, in which based on sizing optimization method and validation by finite element method, a design-3 approach was proposed for manufacturing parts with much lower weight compared to other designs [9].

In addressing an optimization problem, it is essential to study the mesh sensitivity of the computer aided models and hence achieve stress and strains analysis on the optimized part. Park et al (2018) proposed a method of creating computer aided design surfaces from finite element mesh model by using the generated surfaces based on the feature curves to modify the model shape in the designing process [10].

The current advantage in the industrial environment is the availability of optimization software that affords the designer or engineer the liberty of making alterations to the shape and the volume of the proposed design part. And as described in a recent study by Scurtu et al (2015), numerical solvers that utilize mathematical algorithms are employed to iteratively offer the best solutions based on certain required dependent functions and their correlative design variables [11].

Essentially, optimization can be grouped into three classes namely: (a) topology (this addresses the overall layout of the part), (b) sizing (which deals with the mass of the part in relation to design constraints and other variable parameters) and (c)shape [12]. In the evaluation of a part for shape optimization, the difference of work and area between the actual load displacement curve and the desired load displacement curve is determined, hence finding in relation to a specific limit, the optimum shape that represents an acceptable work difference [13].

Topology optimization uses constructive algorithms to reorganize the part in the design space therefore modifying the layout of the part into a complex structure that has higher performance [14] and lower cost due to low material requirements and this positively affects cost of manufacture by reducing waste, and cost of recycle. In the automotive industry for example, low weight and inferably low mass is an ideal trade-off for high performance vehicles such as the jet dragster, a jet-propelled car. In operation, the engine subjects high stress unto its mount which must have a weight as low as possible as its primary 
function is to in conjunction with the brackets, support and maintain the engine's position and balance on the chassis of the vehicle. The mount and brackets must therefore possess significant strength to withstand severe vibration and excessive stresses that may be imposed on them [15]. Sizing optimization therefore is a study that relates the more often than not, the ultimate yield strength and the maximum stress incident on the current model under critical working conditions and finds through iterative processing a way to compensate for the strength requirement without going beyond the desired mass limits.

\section{Methods and materials}

In this paper, the horizontal sheet metal base of a horizontal toggle clamp is optimised for mass reduction using the finite element analysis in the Solid Edge computer aided design software.

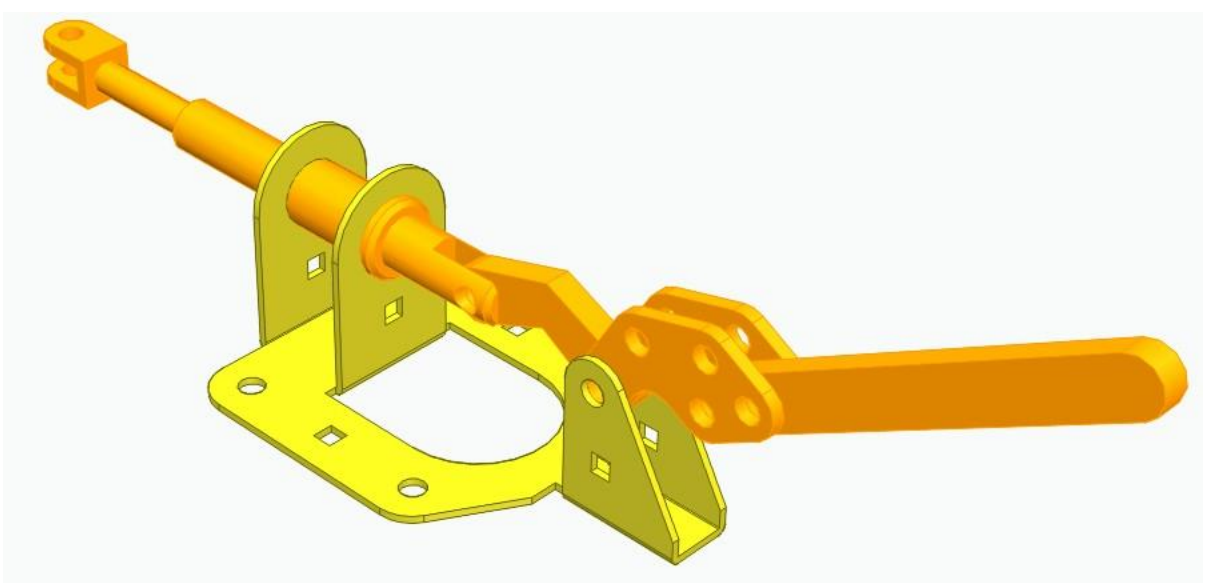

Figure 1 Assembled geometric model of the sheet metal base of the toggle clamp

Toggle clamps are generally used for industrial applications where there is a need to apply high forces for clamping, often where repetitive movements are expected, in order to quickly fix the workpieces in one position safely. The parts and components are modelled and assembled in the Solid Edge software, using the ISO Metric Sheet Metal and the ISO Metric Assembly environments respectively.

\subsection{Material properties}

The sheet metal base of the toggle clamp in this study was made of the ANSI32 Steel with the properties as listed in Table 1. In the Solid Edge, it is designed with the thickness of $5 \mathrm{~mm}$ and it is intended to support a workload of up to $750 \mathrm{~N}$.

\begin{tabular}{|l|l|l|}
\hline SN & Parameter (units) & Value \\
\hline 1 & Mass $(\mathrm{kg})$ & 7.163 \\
\hline 2 & Density $\left(\mathrm{kg} / \mathrm{m}^{3}\right)$ & 7833.000 \\
\hline 3 & Young's Modulus (MPa) & 199947.953 \\
\hline 4 & Poisson's Ratio & 0.290 \\
\hline 5 & Ultimate Stress (MPa) & 358.527 \\
\hline 6 & Yield Stress (MPa) & 262.001 \\
\hline
\end{tabular}

Table 1 Physical and mechanical properties of the sheet metal base 


\section{Results and Discussions}

The analysis was done by experimenting with loading forces of $500 \mathrm{~N}, 750 \mathrm{~N}$ and $1000 \mathrm{~N}$ in magnitude. The $750 \mathrm{~N}$ was a better loading force in terms of safe application of the toggle clamp. The constraints were a fixed point added at all the holes and at the bottom surface of the sheet metal base.

The sheet metal base was analysed for mesh sensitivity as well as its response to applied forces, by checking the stress and strain values. The analysis is compared, and the metal sheet base is optimised by adding holes and slots in the body of the sheet metal base.

\subsection{Mesh sensitivity analysis}

The mesh sensitivity of the sheet metal base plate was made in the Solid Edge software and the result was recorded on the table below, and also by plotting a graph of the mesh size in mm against the time of computation simulation in seconds, factor of safety, von Mises stress, and the displacement. The mesh sensitivity was measured from the size of $2 \mathrm{~mm}$ to $20 \mathrm{~mm}$, and the mesh size of $6 \mathrm{~mm}$ was selected as best fit for the model.
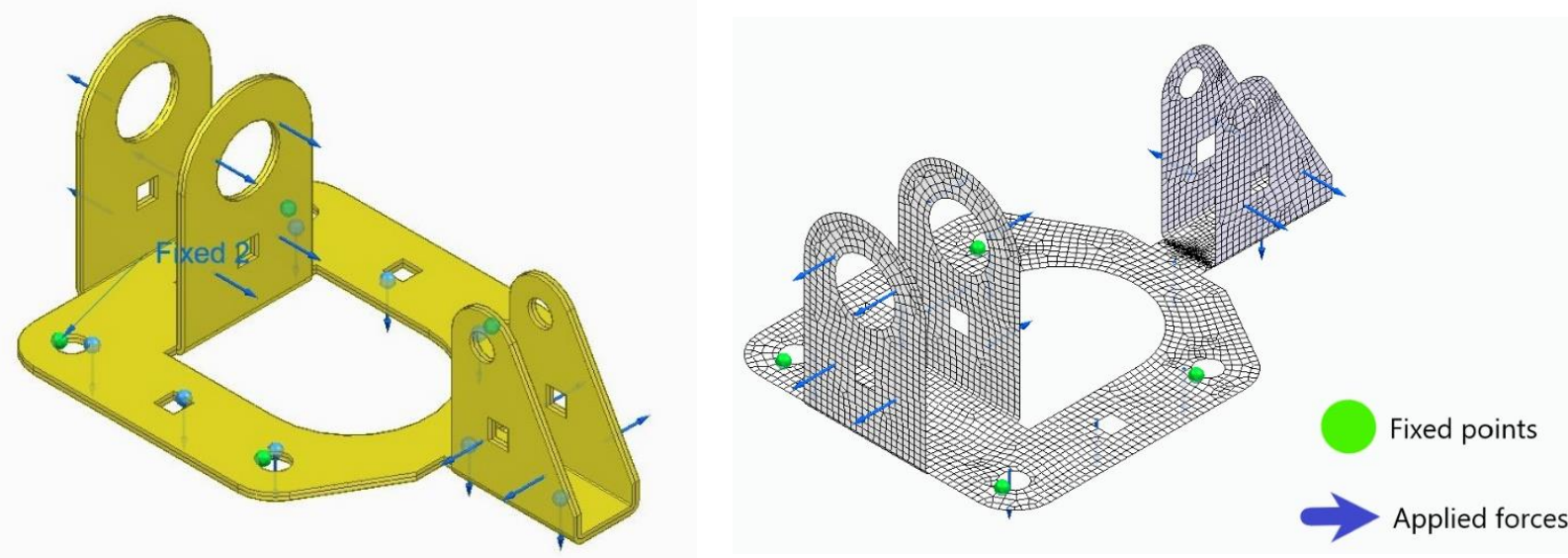

Figure 2 The CAD model with mid-surface line, mesh and forces applied

\begin{tabular}{|c|c|c|c|c|}
\hline $\begin{array}{c}\text { Mesh size } \\
\text { (mm) }\end{array}$ & $\begin{array}{c}\text { Computation } \\
\text { time (s) }\end{array}$ & $\begin{array}{c}\text { Factor of } \\
\text { safety }\end{array}$ & $\begin{array}{c}\text { von Mises } \\
\text { stress (MPa) }\end{array}$ & $\begin{array}{c}\text { Displacemen } \\
\text { t (mm) }\end{array}$ \\
\hline 20 & 5 & 3.75 & 70 & 1.49 \\
\hline 18 & 6 & 3.64 & 71.9 & 1.49 \\
\hline 16 & 6 & 3.48 & 75.4 & 1.49 \\
\hline 14 & 6 & 3.44 & 76.2 & 1.5 \\
\hline 12 & 7 & 3.32 & 79 & 1.51 \\
\hline 10 & 7 & 3.12 & 84 & 1.51 \\
\hline 8 & 8 & 3.05 & 85.8 & 1.52 \\
\hline 6 & 11 & 2.87 & 91.4 & 1.52 \\
\hline 4 & 14 & 2.67 & 98.2 & 1.52 \\
\hline 2 & 47 & 2.15 & 122 & 1.53 \\
\hline
\end{tabular}

Table 2 Mesh sensitivity analysis 

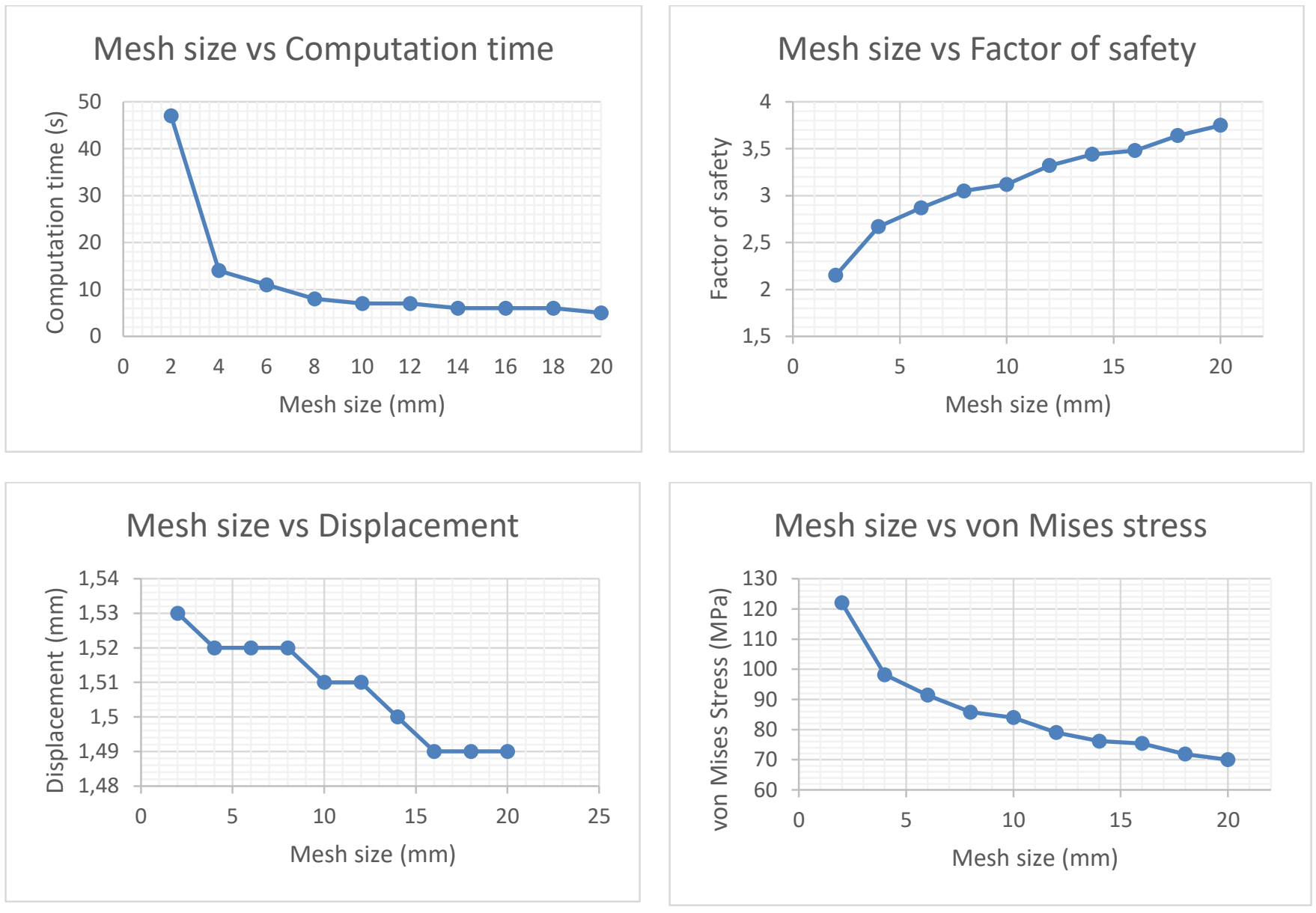

Figure 3 Mesh sensitivity graphs

The maximum displacement was $1.52 \mathrm{~mm}$ and the maximum von Mises stress was $91.4 \mathrm{MPa}$ along the bending areas of the base.
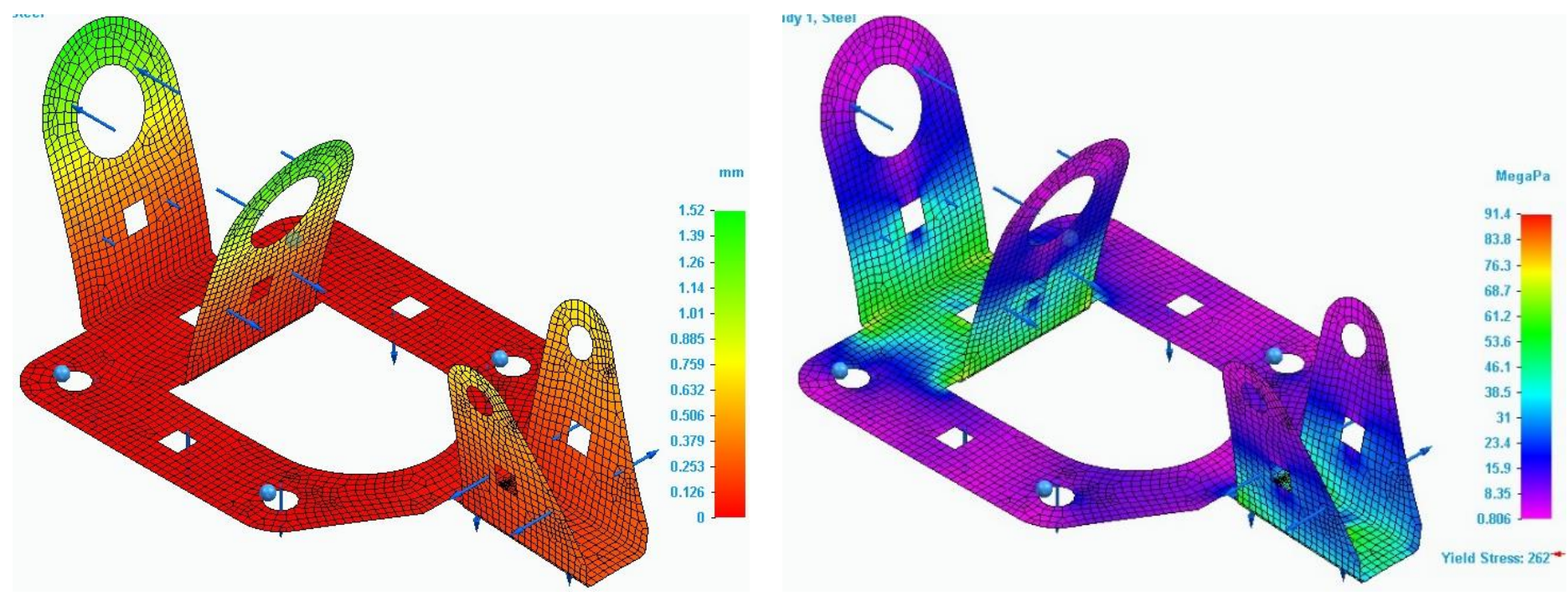

Figure 4 The displacement and von Mises stress 


\subsection{Optimization}

Fourteen optimization iterations were made for the five $750 \mathrm{~N}$ loading forces across the base plate to run the simulation, while it is fixed to its rest. For optimization, the design objective was set to minimize the mass of the base plate from $7.163 \mathrm{~kg}$ as low as possible. The design limits were the von Mises stress to seek between $170 \mathrm{MPa}$ and $210 \mathrm{MPa}$. The design variables were the material thickness measured along the mid-surface of the sheet metal between $2.50 \mathrm{~mm}$ and original $7.00 \mathrm{~mm}$; and to increase the eight slots sizes from the original $20 \mathrm{~mm}$ x $20 \mathrm{~mm}$ square to increase their width up to $30-150 \mathrm{~mm}$ maximum. The optimization results were summarized and presented on the table below, showing the new mass for each optimization iteration.

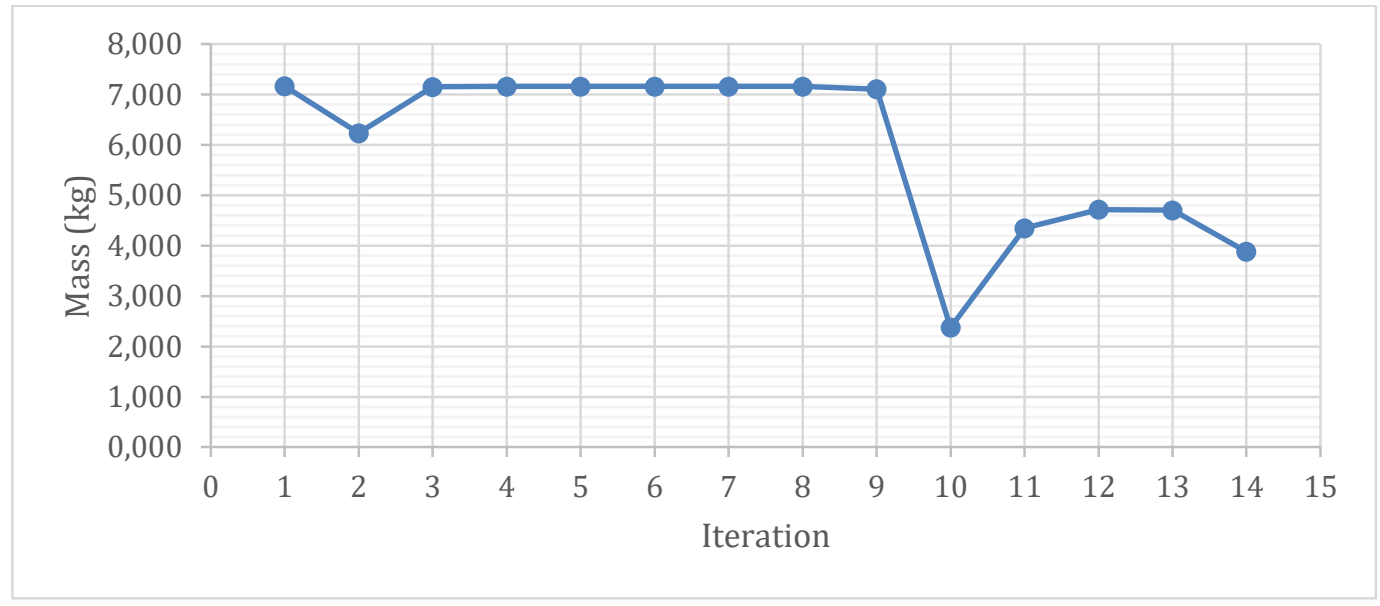

Figure 5 Optimization mass vs iteration results

\subsection{Optimized design}

The $12^{\text {th }}$ iteration was selected as it posed best results in line with the objectives of the study. Based on the optimization results, the slots sizes were increased to remove some material. The thickness of the sheet metal was also reduced from $7 \mathrm{~mm}$ to $5 \mathrm{~mm}$.

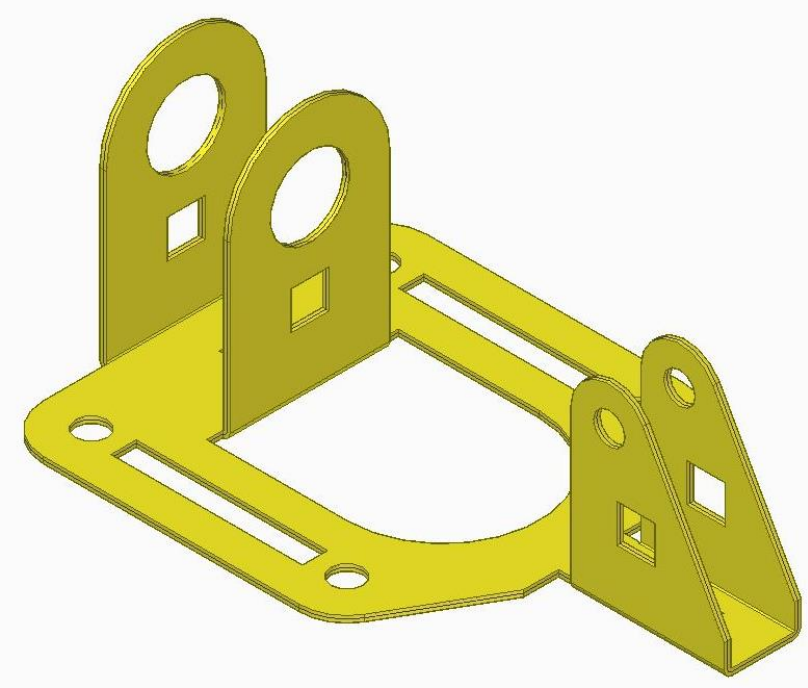

Figure 6 Optimized base design 
As a result, from the optimization, the mass of the base was reduced from $7.163 \mathrm{~kg}$ to $4.713 \mathrm{~kg}$ which is a $34.2 \%$ reduction in mass while still meeting allowable stress with a factor of safety greater than 1.2 by design.

With these results, the optimized clamp base was redesigned and a new FEM analysis was done to check the capability of the optimized design. The fixed constraint, the five $750 \mathrm{~N}$ loads, and the mesh size of $6 \mathrm{~mm}$ was maintained for the FEM analysis of the optimized design as well.
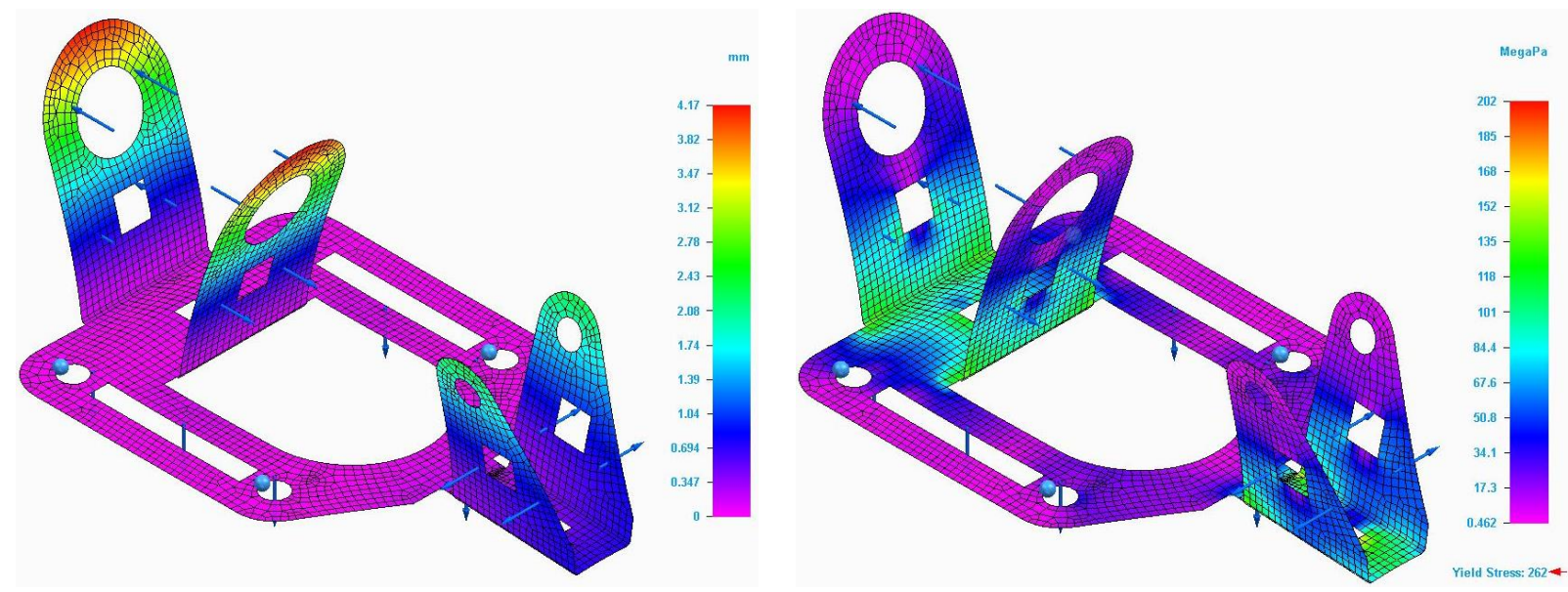

Figure 7 The displacement and von Mises stresses of the optimized design

\section{Conclusion}

Based on the results obtained it is evident that optimization using FEM presents a design advantage as it defines the critical working conditions of the part with its constraints and limits, and ensures a proficient design that is capable of working within those limits. It also ensures less material waste and the ensuing high cost of production due to excess material usage. In addition, this process highlights areas of possible failure and affords the designer the luxury of mitigating the likelihood of operational failure way before the part is even manufactured therefore shortening the cycle of designing, testing and redesigning.

In this study, the base of the toggle clamp was optimized. Mesh analysis was done to select the best mesh type and size for the optimization problem. The smaller the mesh size, the higher the computation time. The objective of optimization was to reduce the mass of the base by minimizing the thickness of the material and increasing the slot sizes, consequently reducing the amount of the required material and the cost of manufacturing. By adding slots in the regions with low stress and by reducing the thickness of the sheet metal from $7 \mathrm{~mm}$ to $5 \mathrm{~mm}$, the mass was reduced from $7.163 \mathrm{~kg}$ to $4.713 \mathrm{~kg}$ which is $34.2 \%$ reduction in mass, while maintaining the maximum allowable stress of $202 \mathrm{MPa}$ and a factor of safety greater than 1.2 value. Another recommendation to ensure a more weight efficient solution is to apply local wall thickness to the stressed areas based on the optimum wall thickness from the optimization and further reduce the thickness of the low stress areas of the toggle clamp without breaching the predetermined safety factor. 


\section{References}

[1] Ferede, N., 2020. Topology Optimization of Automotive sheet metal part using Altair Inspire. International Journal of Engineering and Management Sciences, 5(3), pp.143-150.

[2] Mandal, S.K.R. et al., 2014. Use of cad tool for design and development of rotavator blade. Middle East Journal of Scientific Research, 20(2), pp.171-177.

[3] Park, J.M. et al., 2019. Surface reconstruction from FE mesh model. Journal of Computational Design and Engineering, 6(2), pp.197-208.

[4] Raj, S., 2020. Topology Optimization of Pipeline Bracket for Mass Reduction. International Research Journal of Engineering and Technology, 7(9), pp.948-953.

[5] Scurtu, I.-L., Bodea, S.M., Jurco, A.N., 2016. Design Optimization Method Used In Mechanical Engineering. Journal of Industrial Design and Engineering Graphics, pp.13-17.

[6] Shinde, G.U., Kajale, S.R., 2012. Design Optimization in Rotary Tillage Tool System Components by Computer Aided Engineering Analysis. International Journal of Environmental Science and Development, 3(3), pp.279-282.

[7] Szmyt, W., Gmiterek, D., Dębowski, B., 2018. Optimization of yaw damper bracket, fatigue assessment. In: AIP Conference Proceedings. American Institute of Physics Inc., pp. 1-9.

[8] Tyflopoulos, E., Lien, M., Steinert, M., 2021. Optimization of Brake Calipers Using Topology Optimization for Additive Manufacturing. Applied Sciences, 11(4), pp.1-21.

[9] Vaishnav, A., Sarvaiya, M., Lathiya, P., 2016. Design Optimization of Hydraulic Press Plate using Finite Element Analysis. Int. Journal of Engineering Research and Applications, 6(5), pp.58-66.

[10] Ziech, J. et al., 2003. Design Optimization Method for CAD Structural Components. SAE International., pp1-22.

[11] L.-I. Scurtu, S. Bodi, M. Dragomir. 2015. Optimization Methods Applied in CAD Based Furniture Design, Acta Technica Napocensis, Applied Mathematics, Mechanics and Engineering, vol. 58, issue IV, Nov. 2015, p. 559.

[12] D. Gunwant, A. Misra, 2012. Topology Optimization of Sheet Metal Brackets using ANSYS, MIT International Journal of Mechanical Engineering, MIT Publications, vol. 2, No. 2, Aug. 2012, pp. 120-126.

[13] T. Mankovits, T. Szabó, I. Kocsis, I. Páczelt, 2012, Optimization of the Shape of Axi-Symmetric Rubber Bumpers, Strojniški vestnik - Journal of Mechanical Engineering 60(1), pp. 61-71.

[14] U. Khalid, O. Mustafa, M. A. Naeem, M. Alkhateeb, B. Awad, 2020. Direct Optimization of an Automotive Sheet Metal Part Using ANSYS, International Journal of Engineering and Management Sciences, vol. 5(3).

[15] S. Ramesh, R. Rusovici, R. Handal, M. J. Jensen, 2020. Topology Optimization and Finite Element Analysis of a Dragster Engine Mount, Cogent Engineering, pp. 1-24. 